\title{
Dual-wavelength laser operation in a-cut $\mathrm{Nd}: \mathrm{MgO}: \mathrm{LiNbO}_{3}$
}

\author{
M. Q. Fan, T. Li", S. Z. Zhao, G. Q. Li, D. C. Li, K. J. Yang, W. C. Qiao, and S. X. Li \\ School of Information Science and Engineering, and Shandong Provincial Key Laboratory of Laser Technology and Application, \\ Shandong University, Jinan, 250100, China \\ *Corresponding author: litao@sdu.edu.cn
}

\begin{abstract}
Diode-pumped dual-wavelength a-cut $\mathrm{Nd}: \mathrm{MgO}: \mathrm{LiNbO}_{3}$ lasers near 1085 and $1093 \mathrm{~nm}$ were experimentally and theoretically investigated. The simultaneous dual-wavelength emitting was mainly attributed to the Boltzmann distribution of the occupation in the Stark-split energy-levels in manifold ${ }^{4} I_{11 / 2}$. Under an absorbed pump power of $7.45 \mathrm{~W}$, a maximum continuous wave $(\mathrm{CW})$ output power of $1.23 \mathrm{~W}$ was obtained, giving a slope efficiency of $21.2 \%$. Using Cr:YAG as saturable absorber, the shortest pulse duration of $28 \mathrm{~ns}$ was obtained with a repetition rate of $24 \mathrm{kHz}$, resulting in a peak power of $729 \mathrm{~W}$.
\end{abstract}

Keywords: Dual-wavelength; Diode-pumped; Boltzmann distribution; Passive Q-switching.

\section{Introduction}

Lithium niobate $\left(\mathrm{LiNbO}_{3}\right)$ is a multifunctional crystal belonging to the group of ferroelectric materials combining electro-optic, acousto-optic, and nonlinear optical properties [1]. Additionally, rare-earth-doped $\mathrm{LiNbO}_{3}$ has attracted a lot interest as the lasing performance with nonlinear characteristic and ferroelectric effect could be simultaneously realized in one crystal [2,3]. The first $\mathrm{Nd}: \mathrm{LiNbO}_{3}$ laser operation was realized in 1967, which was limited to a few minutes, because of the pump-induced photorefractive damage due to the photovoltaic effect $[3,4]$. The breakthrough was achieved by the co-doping of $\mathrm{MgO}$ [2,5]. Due to the ${ }^{4} F_{3 / 2} \rightarrow{ }^{4} I_{11 / 2}$ transition [7], laser oscillation could be achieved in the high-gain polarization ( $\pi$-polarization) at $1085 \mathrm{~nm}$ as well as in the low-gain polarization ( $\sigma$-polarization) at $1093 \mathrm{~nm}$ [2,5]. Dual-wavelength emitting from a single laser medium possesses huge potential in the applications of high-precision laser metrology, laser spectroscopy, satellite laser ranging, analysis of the atmosphere, and THz research [8,9]. However, the stable, synchronous dual-wavelength laser has not been acquired in $\mathrm{Nd}: \mathrm{MgO}: \mathrm{LiNbO}_{3}$. In c-cut $\mathrm{Nd}: \mathrm{MgO}: \mathrm{LiNbO}_{3}$ laser, only the $\sigma$-polarization oscillation at $1093 \mathrm{~nm}$ along the cavity axis exists and the $\pi$-polarization laser is completely suppressed [10]. Using a-cut $\mathrm{Nd}: \mathrm{MgO}: \mathrm{LiNbO}_{3}$ is a possible way to get the dual-wavelength radiation, which has never been observed in the previous reports, due to the ultra-low output power of tens of milliwatts [2,5,6,11].

Q-switching is a widely used technique for producing high-energy laser pulses with nanosecond duration. The active internal Q-switched Nd:MgO: $\mathrm{LiNbO}_{3}$ laser was first demonstrated in 1987 with a peak power of $\sim 5 \mathrm{~W}$ [12]. In 2008, Y. H. Chen et al. realized a laser-diode-pumped, electro-optically internal Q-switched $\mathrm{Nd}: \mathrm{MgO}: \mathrm{LiNbO}_{3}$ laser operation, obtaining a peak power of $\sim 88 \mathrm{~W}$ [13]. Until now, the passively Q-switched $\mathrm{Nd}: \mathrm{MgO}: \mathrm{LiNbO}_{3}$ lasers have not been reported, which own the advantages of simple design, compact structure, and stable output. Compared with other materials, such as topological insulators (TIs) [14], molybdenum sulfide $\left(\mathrm{MoS}_{2}\right)$ [15,16], and black phosphorus (BP) 
[17], $\mathrm{Cr}^{4+}: \mathrm{YAG}$ is identified a proper saturable absorber (SA) near $1 \mu \mathrm{m}$, because of its large absorption cross section, high thermal conductivity, and high damage threshold [18].

In this paper, the laser properties of a-cut $\mathrm{Nd}: \mathrm{MgO}: \mathrm{LiNbO}_{3}$ crystal were experimental investigated in both $\mathrm{CW}$ and passive Q-switching cases. A maximum $\mathrm{CW}$ output power of $1.23 \mathrm{~W}$ was obtained at the absorbed pump power of $7.45 \mathrm{~W}$, corresponding to an optical conversion efficiency of $16.5 \%$ and a slope efficiency of $21.2 \%$. Employing a $\mathrm{Cr}^{4+}:$ YAG crystal as SA, the Q-switched laser with a repetition rate of $24 \mathrm{kHz}$ and $28 \mathrm{~ns}$ pulses was achieved, resulting in a peak power of $729 \mathrm{~W}$. In addition, dual wavelength emitting at 1085 and $1093 \mathrm{~nm}$ was first experimentally realized and theoretically analyzed based on the Boltzmann distribution.

\section{Experimental setup}

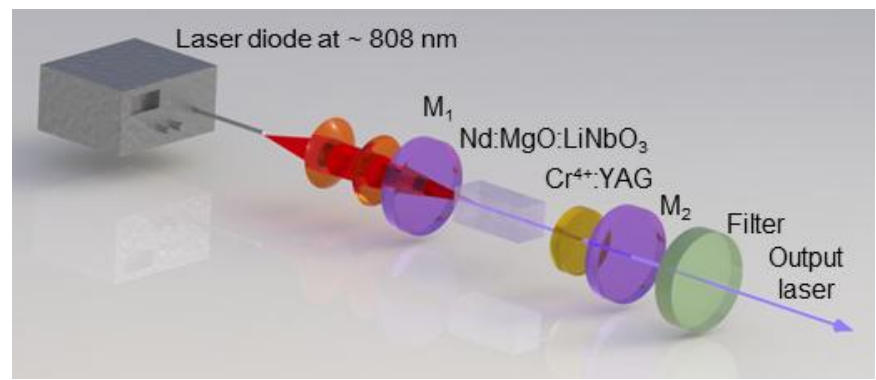

Fig. 1. Schematic diagram of the experimental setup. The pump source is launched into the a-cut $\mathrm{Nd}: \mathrm{MgO}: \mathrm{LiNbO}_{3}$ through a 1:1 imaging module and the optical cavity length is $\sim 3.5$ $\mathrm{cm}$.

The schematic diagram of $\mathrm{Nd}: \mathrm{MgO}: \mathrm{LiNbO}_{3}$ laser is depicted in Fig. 1. The pump source was a fiber-coupled laser diode (Coherent, FAP system) with a maximum output power of $30 \mathrm{~W}$ at $808 \mathrm{~nm}$, which had a $400 \mu \mathrm{m}$ core diameter and a numerical aperture (NA) of 0.22 . The pump light was launched into the $\mathrm{Nd}: \mathrm{MgO}: \mathrm{LiNbO}_{3}$ crystal through a 1:1 imaging module with a spot diameter of 400 $\mu \mathrm{m}$. The $3.5 \mathrm{~cm}$-long compact linear cavity was adopted to achieve stable and efficient passively Q-switched laser performance. $\mathrm{M}_{1}$ was a concave mirror $(\mathrm{R}=100 \mathrm{~mm})$ working as the input mirror, the entrance surface was anti-reflectivity (AR) coated around $808 \mathrm{~nm}$, while the other facet was high-transmission (HT) coated around $808 \mathrm{~nm}(\mathrm{~T}>85 \%)$ with high-reflection (HR) coated ranging from 1000 to $1200 \mathrm{~nm}(\mathrm{R}>99 \%) . \mathrm{M}_{2}$ was a flat mirror acting as the output coupler (OC). In the experiment, OCs with two different transmissions of $4 \%$ and $6.5 \%$ were used. A filter was put behind $\mathrm{M}_{2}$ to leach the pump light. The $\mathrm{Cr}^{4+}$ :YAG with small-signal transmission of $93 \%$ was placed at the beam waist near $\mathrm{M}_{2}$. The $\mathrm{Nd}: \mathrm{MgO}: \mathrm{LiNbO}_{3}$ crystal, which was doped with $\mathrm{Nd}^{3+}(1.0$ at. \%) and $\mathrm{MgO}$ (5.0 at. \%), was processed into small dimensions of $3 \mathrm{~mm} \times 3 \mathrm{~mm} \times 10 \mathrm{~mm}$. The end plane diffraction angle of $\mathrm{Nd}: \mathrm{MgO}: \mathrm{LiNbO}_{3}$ was measured to be $17.07^{\circ}$ by using X-ray diffraction (XRD) method, which indicated that the light passing-direction in crystal was parallel with the a-axis (the deviation angle was $\sim 0.35^{\circ}$ ). The selected crystal was wrapped in indium foil and mounted in a copper block cooled by a water-cooler to $13{ }^{\circ} \mathrm{C}$ during the whole experiment process. A PM100D power meter with a S314C power head (Thorlabs Inc., USA) was employed for measuring the average output power. The spectra were measured by a Wavescan Laser spectrometer (Resolution: $0.4 \mathrm{~nm}$, APE GmbH, Germany). The laser pulse trains were detected by a fast InGaAs photo-detector with a rise time of $400 \mathrm{ps}$ (New Focus model 1611, Newport Inc. USA) and recorded by a DPO 7104C digital phosphor oscilloscope (1 GHz bandwidth and $20 \mathrm{GS} / \mathrm{s}$ sampling rate, Tektronix Inc., USA).

\section{Experimental results and discussions}




\subsection{CW operation}

The CW output powers was measured and shown in Fig. 2, which was linearly increased with the absorbed pump power. The maximum power of $1.23 \mathrm{~W}$ was obtained at an absorbed pump power of $7.45 \mathrm{~W}$ (incident pump power of $8.76 \mathrm{~W}$ ) with the $\mathrm{OC}$ of $\mathrm{T}=6.5 \%$, corresponding to an optical conversion efficiency of $16.4 \%$ and a slope efficiency of $21.2 \%$. Compared to the OC of $\mathrm{T}=4 \%$, both the optical conversion efficiency and the slope efficiency were dramatically improved. Thus $\mathrm{T}=6.5 \%$ was considered to be closer to the optical optimum transmission for output power. Furthermore, this was the first demonstration of watt-level CW laser operation with the a-cut $\mathrm{Nd}: \mathrm{MgO}: \mathrm{LiNbO}_{3}$.

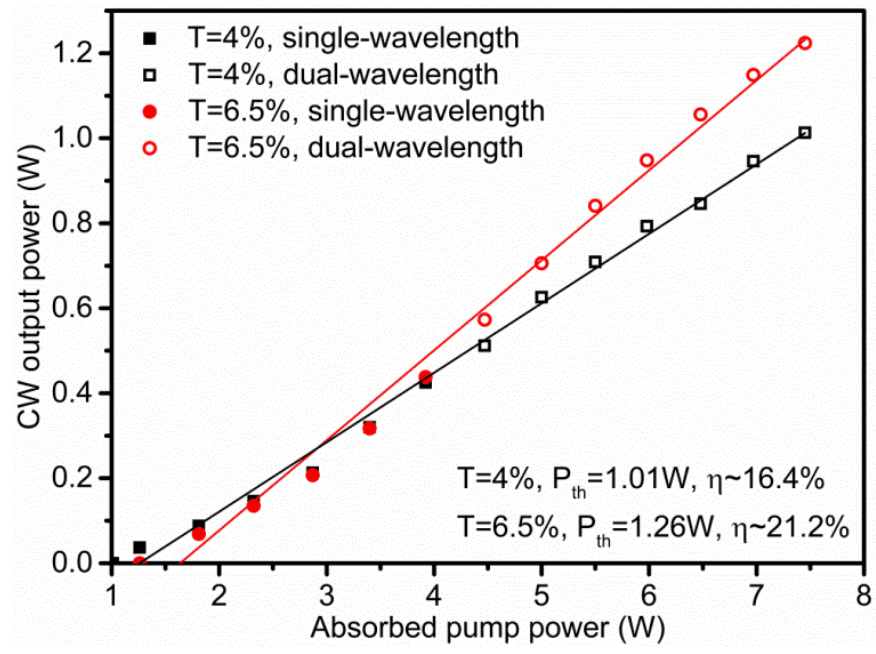

Fig. 2. $\mathrm{CW}$ laser performance of the a-cut $\mathrm{Nd}: \mathrm{MgO}: \mathrm{LiNbO}_{3}$ crystal. Watt-level laser operation was realized with a diode laser pumping at $808 \mathrm{~nm}$.

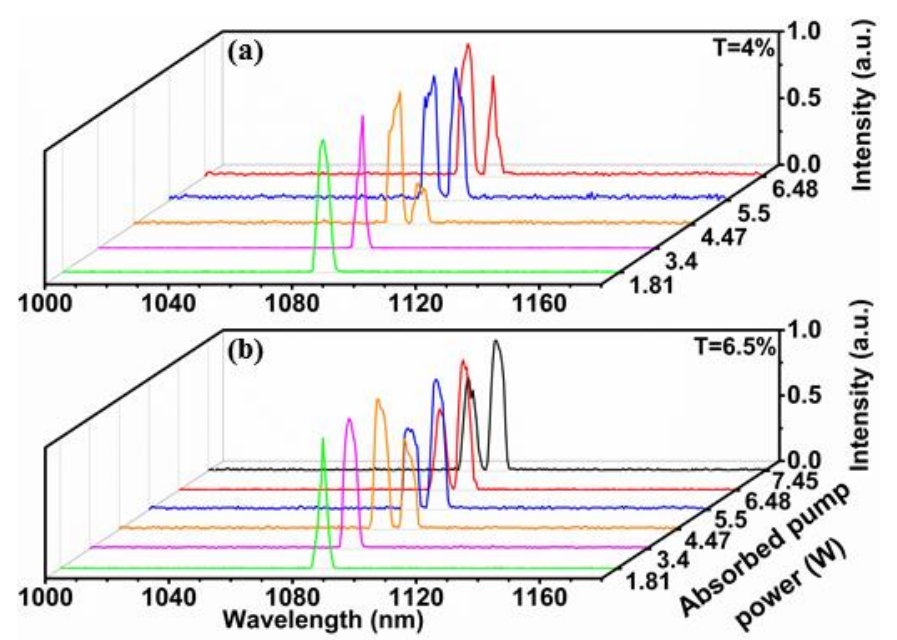

Fig. 3. Output spectra of the CW Nd:MgO: $\mathrm{LiNbO}_{3}$ laser, at different absorbed pump power levels: (a) with the $\mathrm{OC}$ of $\mathrm{T}=4 \%$; (b) with the $\mathrm{OC}$ of $\mathrm{T}=6.5 \%$. Dual-wavelength emission was observed for the first time.

The laser spectra were recorded at different absorbed pump power levels, which are shown in Fig. 3. The output spectra were dramatically changed at different pump power. At low pump power (less than $4.47 \mathrm{~W}$ ), the $\mathrm{Nd}: \mathrm{MgO}: \mathrm{LiNbO}_{3}$ lasers only ran at $1085 \mathrm{~nm}$ for $\pi$-polarization. As soon as the absorbed pump power exceeded $4.47 \mathrm{~W}$ (incident pump power exceeded $5.31 \mathrm{~W}$ ), the laser stepped into dual-wavelength operation at 1085 and $1093 \mathrm{~nm}$, which was realized for the first time.

\subsection{Q-switching operation}

The characteristic of Q-switched a-cut $\mathrm{Nd}: \mathrm{MgO}: \mathrm{LiNbO}_{3}$ laser was investigated by employing 
$\mathrm{Cr}^{4+}$ :YAG as SA. The average output powers as a function of absorbed pump powers are shown in Fig. 4. The threshold of Q-switched $\mathrm{Nd}: \mathrm{MgO}: \mathrm{LiNbO}_{3}$ laser was increased by the additional losses introduced by $\mathrm{Cr}^{4+}$ :YAG, which was estimated to be $3.1 \%$ according to the threshold values of the $\mathrm{CW}$ and Q-switched lasers. The additional losses also decreased the slope efficiency. At the OC of $\mathrm{T}=6.5 \%$, the laser generated a maximum average output power of $490 \mathrm{~mW}$ with a slope efficiency of $10.5 \%$, respecting to an absorbed pump power of $7.45 \mathrm{~W}$. At the same pump power, the maximum average output power of $365 \mathrm{~mW}$ was achieved with the $\mathrm{OC}$ of $\mathrm{T}=4 \%$.

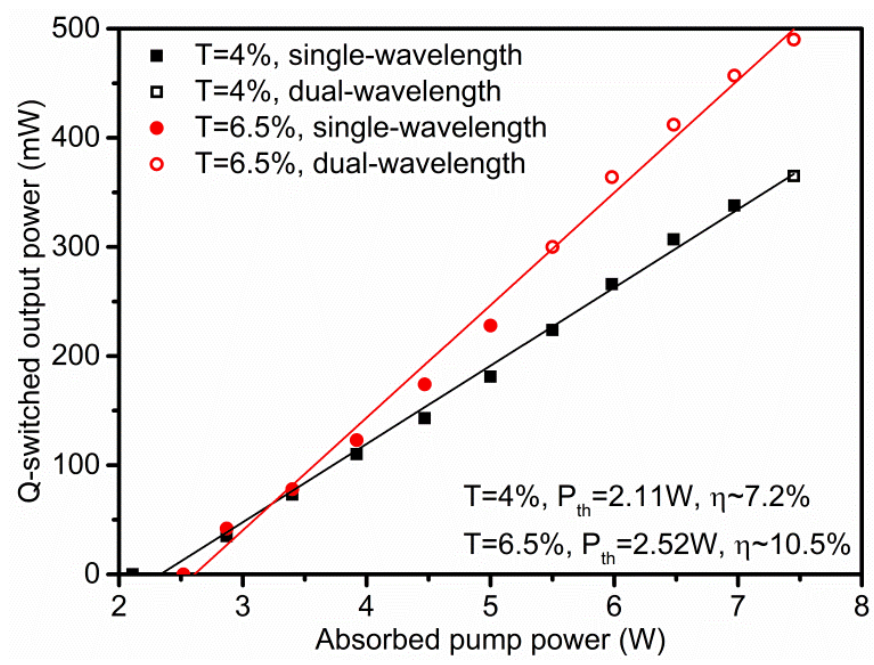

Fig. 4. Average output power of the Q-switched $\mathrm{Nd}: \mathrm{MgO}: \mathrm{LiNbO}_{3}$ laser using $\mathrm{Cr}^{4+}$ :YAG, depending on absorbed pump power. Compared to the CW laser, the thresholds were increased and the slope efficiencies were decreased by the additional losses of the SA.

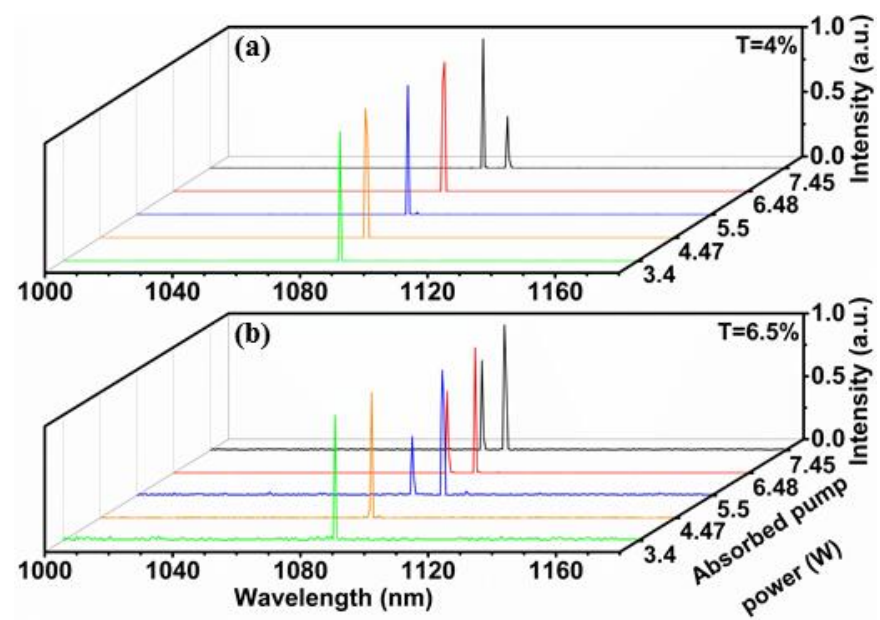

Fig. 5. Output spectra of the Q-switched $\mathrm{Nd}: \mathrm{MgO}: \mathrm{LiNbO}_{3}$ laser, at different absorbed pump power levels: (a) with the OC of $\mathrm{T}=$ $4 \%$; (b) with the $\mathrm{OC}$ of $\mathrm{T}=6.5 \%$. Compared with the laser spectra in $\mathrm{CW}$ laser, the spectral profiles were compressed by the SA.

The dual-wavelength operation at 1085 and $1093 \mathrm{~nm}$ was also realized in the Q-switched lasers, as shown in Fig. 5. Compared with the CW operation, the $1093 \mathrm{~nm}$ radiation thresholds were increased and the spectra were narrowed by the insert loss of SA. When the average output power surpassed $300 \mathrm{~mW}$, (absorbed pump power levels of $7.45 \mathrm{~W}$ and $5.5 \mathrm{~W}$ with the OCs of $\mathrm{T}=4 \%$ and $\mathrm{T}=6.5 \%$, respectively), the $1093 \mathrm{~nm}$ emission obtained enough gain for compensating the intracavity loss, the dual-wavelength operation could be accordingly achieved. 
The variations of pulse repetition rates and pulse durations with absorbed pump powers are shown in Fig. 6. The pulse repetition rates increased with the augment of absorbed pump powers, while the pulse durations varied in an opposite manner. At an absorbed pump power of $7.45 \mathrm{~W}$ and the $\mathrm{OC}$ of $\mathrm{T}=6.5 \%$, $28 \mathrm{~ns}$ pulses were generated under a repetition rate of $24 \mathrm{kHz}$. With the $\mathrm{OC}$ of $\mathrm{T}=4 \%, 31 \mathrm{~ns}$ pulses with a repetition rate of $22 \mathrm{kHz}$ were achieved.

Fig. 7 shows the temporal pulse trains and profiles at the absorbed power of $7.45 \mathrm{~W}$ and $\mathrm{T}=6.5 \%$. The pulse to pulse fluctuation was less than $5 \%$, which indicated a satisfactory pulse-to-pulse stability.

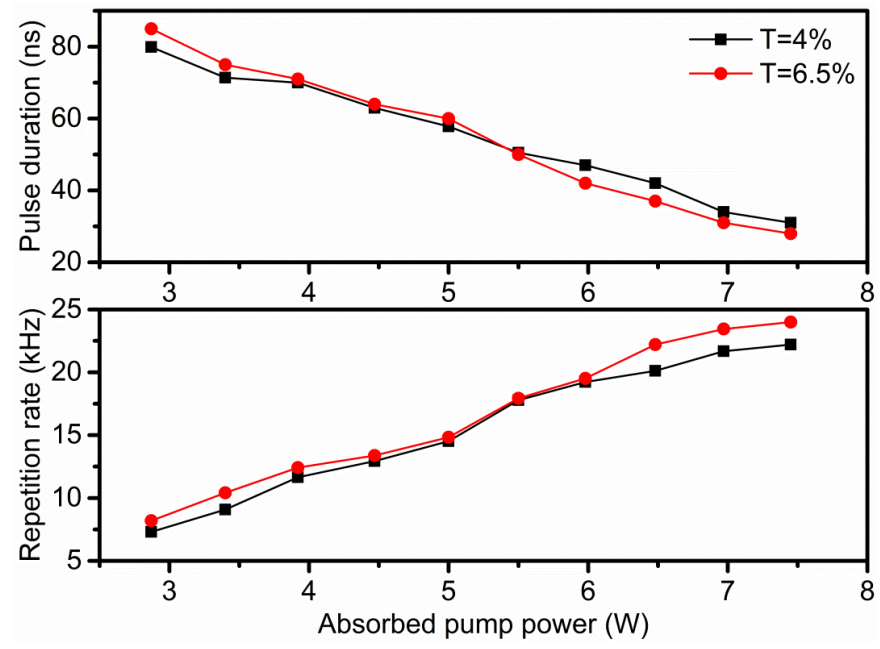

Fig. 6. Pulse repetition rate and pulse duration versus absorbed pump power. The shortest pulse duration of $28 \mathrm{~ns}$ was observed, with a repetition rate of $24 \mathrm{kHz}$.

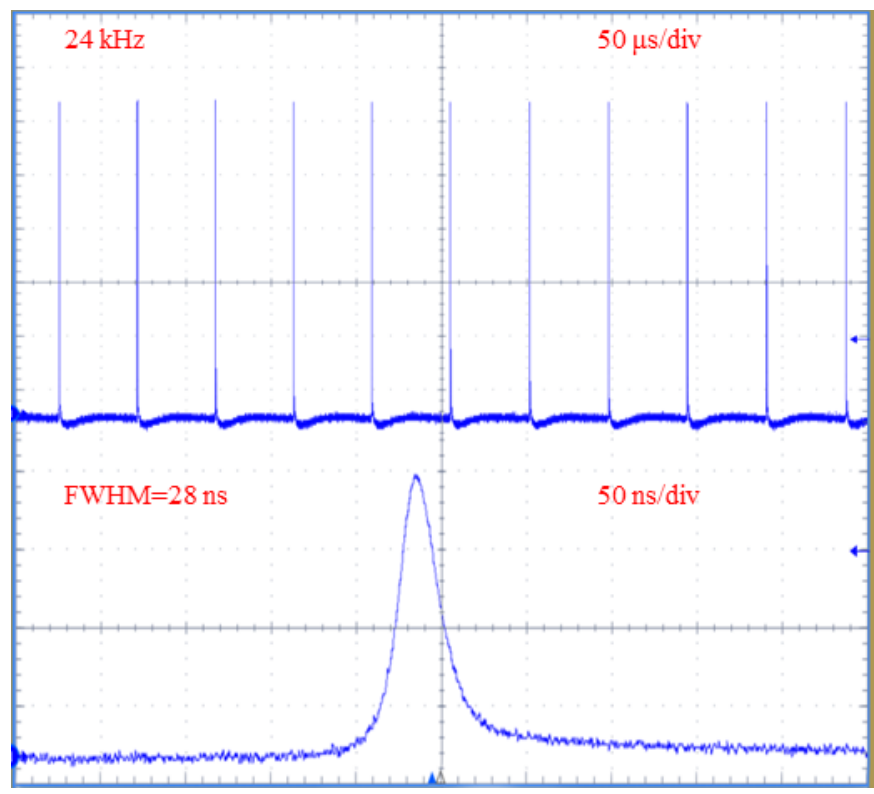

Fig. 7. Temporal traces of Q-switched pulse train with the $6.5 \% \mathrm{OC}$, under the absorbed pump power of $7.45 \mathrm{~W}$. There are no satellite pulses, indicating that the dual-wavelength emission is well synchronous.

Fig. 8 depicts the functions of pulse energies and peak powers, which were positively related to the absorbed pump powers. Under an absorbed power of $7.45 \mathrm{~W}, 16.5 \mu \mathrm{J}$ and $20.4 \mu \mathrm{J}$ pulse energies were achieved by employing the OCs of $\mathrm{T}=4 \%$ and $\mathrm{T}=6.5 \%$, respectively. The highest peak power of 729 $\mathrm{W}$ was obtained with the $\mathrm{OC}$ of $\mathrm{T}=6.5 \%$, which was about 0.4 time higher than the value achieved at $\mathrm{T}=4 \%$. 


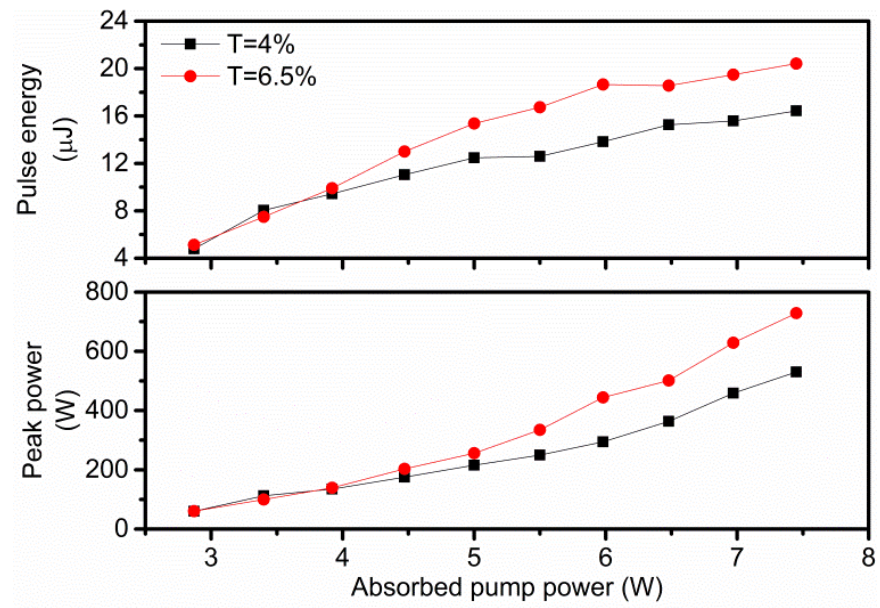

Fig. 8. Pulse energies and peak powers versus absorbed pump power. The maximum pulse energy was $20.4 \mu \mathrm{J}$, resulting in a peak power of $729 \mathrm{~W}$.

\subsection{Theoretical analysis}

In the host crystals with a strong crystalline field, manifold ${ }^{4} I_{11 / 2}$ in $\mathrm{Nd}^{3+}$ ions exhibit large energy level splitting, as shown in Fig. 9 (inset) (The value of energy is given in $\mathrm{cm}^{-1}$ ). The $R_{l} \rightarrow 2$ (1) and $R_{l} \rightarrow 3$ (2) transitions produce the dual-wavelength emissions at 1085 and $1093 \mathrm{~nm}$, respectively [19]. The stimulated emission cross section for $\pi$-polarization $\left(5.1 \times 10^{-19} \mathrm{~cm}^{2}\right)$ is roughly 1.8 times higher than that for $\sigma$-polarization $\left(1.8 \times 10^{-19} \mathrm{~cm}^{2}\right)$ at room temperature [2, 7], which makes it difficult for the 1093 $\mathrm{nm}$ laser to oscillate synchronously. However, the Boltzmann distribution in the ground-state $\left({ }^{4} I_{11 / 2}\right)$, which is sensitive to the temperature, can induce the vibration of the population-inversion density in these Stark-split energy-levels, accordingly making a possibility for $1093 \mathrm{~nm}$ laser oscillation.

The temperature distribution in the $\mathrm{Nd}: \mathrm{MgO}: \mathrm{LiNbO}_{3}$ crystal can be calculated by the Finite Element Method [20]. The occupation factors follow the Boltzmann distribution, and the intensity of (1) and (2) transitions $I_{R i}(i=2,3)$ can be given by

$I_{R i} \propto A_{R i} v_{R i} N_{R}\left(1-n_{i}\right)$,

where $A_{R i}$ is the spontaneous transition probability, $v_{R i}$ is the frequency of the radiation, $N_{R}$ is the population of the level $R_{l}$, and $n_{i}(i=2,3)$ is the occupation number of particles in levels 2 and 3 ,

$$
n_{i}=\frac{1}{1+\exp \frac{E_{i}}{k_{B} T}},
$$

where $E_{i}(i=2,3)$ is the energy separation between level $i$ and the ground level, $k_{B}$ is Boltzmann's constant, $T$ is the absolute temperature. The ratio of the two fluorescence intensities can be achieved by

$$
R=\frac{I_{R 3}}{I_{R 2}}=\frac{A_{R 3} v_{R 3} N_{R}}{A_{R 2} v_{R 2} N_{R}} \cdot \frac{1-n_{3}}{1-n_{2}} .
$$

Substituting Eq, (4) into Eq. (5), we obtain

$$
R=C_{1} \frac{\left(1+\exp \frac{E_{2}}{k_{B} T}\right) \cdot \exp \frac{E_{3}-E_{2}}{k_{B} T}}{\left(1+\exp \frac{E_{3}}{k_{B} T}\right)},
$$

where $C_{1}$ is a constant coefficient, which can be estimated. It is apparent that the fluorescence intensity ratio is a function of the temperature, which was verified experimentally in 1969 [21]. Furthermore, according to the Fuchtbauer-Ladenbury formula, the effective stimulated-emission cross section can be 
calculated $[2,22]$ :

$\sigma_{\lambda}=\frac{3 \lambda^{5} \beta_{j} I(\lambda)}{8 \pi n^{2} c \tau \int \lambda I d \lambda}$

where $I$ is the fluorescence intensity as a function of wavelength, $I(\lambda)$ is the fluorescence intensity at wavelength $\lambda, n$ is the material refractive index, $c$ is the speed of light, $\tau$ is the radiative lifetime of upper laser level, and $\beta_{j}$ is the branching ratio, which has been measured to be 0.44 for ${ }^{4} F_{3 / 2} \rightarrow{ }^{4} I_{11 / 2}$. Eq.

(7) shows that $\sigma_{\lambda}$ is directly proportional to $I(\lambda) \lambda^{5}$, with a scale factor $3 \beta_{j} / 8 \pi c n^{2} \tau \int \lambda I d \lambda$. So the stimulated-emission cross section ratio $R_{e}$ can be expressed as

$R_{e}=\left(\lambda_{1093}^{5} / \lambda_{1085}^{5}\right) R \approx 1.0374 R$.

The simulation results are illustrated in Fig. 9. The temperature and the stimulated-emission cross section linearly increase with absorbed pump power. At an absorbed pump power of $4.47 \mathrm{~W}$, where the dual-wavelength oscillation launched, the theoretical temperature and cross section ratio reach $378.2 \mathrm{~K}$ and 0.49 , respectively. Compared to the case of room temperature $(\sim 0.35)$, the stimulated-emission cross section ratio is risen $\sim 40 \%$. Moreover, the actual temperature in the crystal must be much higher than the simulated data induced by the gaps between the crystal and the heat sink, accordingly the actual stimulated-emission cross section ratio might be even higher. Therefore, the appearance of the $1093 \mathrm{~nm}$ laser operation is reasonable. The liner increase of stimulation-emission cross section ratio $R_{e}$ with the absorbed pump power induces a stronger and stronger $1093 \mathrm{~nm}$ radiation, which is generally consistent with the spectra measurement, as shown in Fig. 3 and Fig.5.

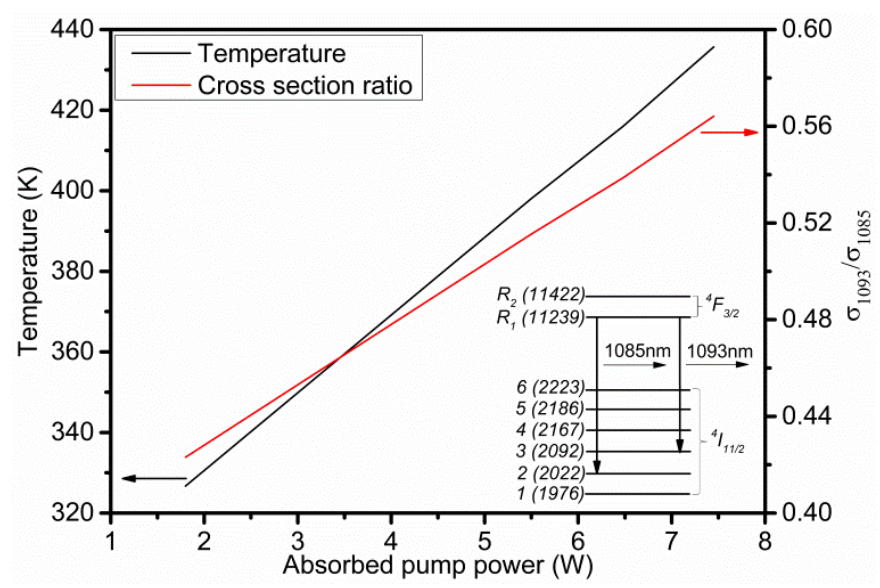

Fig. 9. Theoretical temperature in the center of the pumped facet and stimulated-emission cross section ratio $\left(\sigma_{1093} / \sigma_{1085}\right)$ versus absorbed pump power, and (inset) Stark-split energy-level diagram of $\mathrm{Nd}^{3+}$ in $\mathrm{Nd}: \mathrm{MgO}: \mathrm{LiNbO}_{3}$.

To further investigate the threshold of the $1093 \mathrm{~nm}$ radiation, the following formula is used to estimate the threshold pump power:

$P_{t h}=(L-\ln R) \frac{A h v_{p}}{2 \sigma_{\lambda} \tau \eta_{p e}}$,

where $h v_{p}$ is the single-photon energy of the pump light, $L$ is the intrinsic loss, $R$ is the reflectivity of the output coupler, $A$ is the cross section of the gain medium, and $\eta_{p e}$ is the pump efficiency. Eq. (9) reveals that the threshold pump power is inversely proportional to the stimulated-emission cross section. With a stimulated-emission cross section ratio $\left(\sigma_{1085} / \sigma_{1093}\right)$ of $\sim 2.5$, the theoretical threshold power for 
the CW $1093 \mathrm{~nm}$ laser should be $2.5 \mathrm{~W}$. In fact, in our experiment, the $1093 \mathrm{~nm}$ laser did not appear until the absorbed pump power exceeded $4.47 \mathrm{~W}$. It is because of the photon extraction induced by the $1085 \mathrm{~nm}$ oscillation, and the $1093 \mathrm{~nm}$ laser need much higher pump power to reach the threshold.

\section{Conclusion}

In conclusion, the dual-wavelength laser operations of a-cut $\mathrm{Nd}: \mathrm{MgO}: \mathrm{LiNbO}_{3}$ crystal at 1085 and 1093 $\mathrm{nm}$ were experimentally realized and theoretically analyzed for the first time. A maximum $\mathrm{CW}$ output power of $1.23 \mathrm{~W}$ was achieved at the absorbed pump power of $7.45 \mathrm{~W}$, corresponding to a slope efficiency of $21.2 \%$. Employing $\mathrm{Cr}^{4+}$ :YAG as SA, $28 \mathrm{~ns}$ laser pulses with a repetition rate of $24 \mathrm{kHz}$, and peak power of $729 \mathrm{~W}$ could be generated.

\section{Acknowledgement}

This work was supported by the National Science Foundation for Distinguished Young Scholars of China (No. 61308020), the Open Fund of the State Key Laboratory of Luminescent Materials and Devices (South China University of Technology, No. 2014-skllmd-03), and Independent Innovation Foundation of Shandong University, IIFSDU (2082014TB011).

\section{References}

[1] L. Arizmendi, Phys. Stat. Sol. (a) 201 (2004) 253-283.

[2] T. Y. Fan, A. Cordova-Plaza, M. J. F. Digonnet, R. L. Byer, H. J. Shaw, J. Opt. Soc. Am. B 3 (1986) 140-148.

[3] I. P. Kaminow, L. W. Stulz, IEEE J. Quant. Electron. QE-11 (1975) 306-308.

[4] N. F. Evlanova, A. S. Kovalev, V. A. Koptsik, L. S. Kornienko, A. M. Prokhorov, L. N. Rashkovich, JETP Lett. 5 (1967) 291-292.

[5] A. Cordova-Plaza, T. Y. Fan, M. J. F. Digonnet, R. L. Byer, H. J. Shaw, Opt. Lett. 13 (1988) 209-211.

[6] G. D. Laptev, A. A. Novikov, A. S. Chirkin, V. V. Firsov, N. V. Kravtsov, Proc. SPIE 4268 (2001) 26-35.

[7] R. Burlot, R. Moncorgé, H. Manaa, G. Boulon, Y. Guyot, J. Garcia Solé, D. Cochet-Muchy, Opt. Mater. 6 (1996) 313-330.

[8] Y. F. Chen, S. W. Tsai, S. C. Wang, Y. C. Huang, T. C. Lin, B. C. Wong, Opt. Lett. 27 (2002) 1809-1811.

[9] P. Zhao, S. Ragam, Y. J. Ding, I. B. Zotova, Opt. Lett. 36 (2011) 4818-4820.

[10] R. Li, C. Xie, J. Wang, X. Liang, K. Peng, G. Xu, IEEE J. Quant. Electron. 29 (1993) 2419-2420.

[11] N. MacKinnon, C. J. Norrie, B. D. Sinclair, J. Opt. Soc. Am. B 11 (1994) 519-522.

[12] A. Cordova-Plaza, M. J. F. Digonnet, H. J. Shaw, IEEE J. Quant. Electron. QE-23 (1987) 262-266.

[13] Y. H. Chen, Y. C. Chang, C. H. Lin, T. Y. Chung, Opt. Express 16 (2008) 2048-2055.

[14] F. Q. Jia, H. Chen, P. Liu, Y. Z. Huang, Z. Luo, IEEE J. Sel. Topics Quan. Elec. 21 (2015) 1601806.

[15] B. Xu, Y. J. Cheng, Y. Wang, Y. Z. Huang, J. Peng, Z. Q. Luo, H. Y. Xu, Z. P. Cai, J. Weng, R. Moncorgé, Opt. Express 22 (2014) 28934-28940.

[16] H. Zhang, S. B. Lu, J. Zheng, J. Du, S. C. Wen, D. Y. Tang, K. P. Loh, Opt. Express 22 (2014) 7249-7260.

[17] Y. Chen, G. B. Jiang, S. Q. Chen, Z. N. Guo, X. F. Yu, C. J. Zhao, H. Zhang, Q. L. Bao, S. C. Wen, D. Y. Tang, D. Y. Fan, Opt. Express 23 (2015) 12823-12833.

[18] Y. Ma, H. Li, J. Lin, X. Yu, Opt. Laser Technol. 43 (2011) 1491-1494.

[19] J. O. Tocho, J. A. S. Garcia, F. Jaque, J. G. Solé, J. Appl. Phys. 70 (1991) 5582-5586.

[20] T. Li, S. Z. Zhao, Z. Zhuo, Y. G. Wang, Opt. Commun. 282 (2009) 940-943.

[21] L. F. Johnson, A. A. Ballman, J. Appl. Phys. 40 (1969) 297-302.

[22] W. F. Krupke, M. D. Shinn, J. E. Marion, J. A. Caird, S. E. Stokowski, J. Opt. Soc. Am. B 3 (1986) 102-114. 